Short Communication

\title{
Influence of AC interference on Crack Initiation Behavior of Pipeline Steel in High pH Solution
}

\author{
Min Zhu*, Yongfeng Yuan, Qiang Zhang, Simin Yin, Shaoyi Guo
}

School of Mechanical Engineering \& Automation, Zhejiang Sci-Tech University, Hangzhou 310018, PR China

*E-mail: zmii666@126.com

doi: $10.20964 / 2019.02 .39$

Received: 30 October 2019 / Accepted: 26 November 2018 / Published: 5 January 2019

Stress corrosion cracking (SCC) behavior of U-bend samples of X80 steel under AC application was investigated in high $\mathrm{pH}$ solution by scanning electron microscopy (SEM), macroscopic observation and polarization curves. The results show that there is a remarkable difference in corrosion morphologies of steel samples tested with or without AC current. AC application enhances the corrosion of X80 steel, and results in the occurrence of pitting corrosion. With the increasing AC current density, the corrosion degree of steel increases and the pits become more apparently. The pitting corrosion generated due to applied AC induces and facilitates the crack initiation, the greater of AC current density, the more cracks are initiated from the pits, and thus increases the SCC susceptibility of the steel.

Keywords: Pipeline steel; SCC initiation; AC application; Pitting corrosion

\section{$\underline{\text { FULL TEXT }}$}

(C) 2019 The Authors. Published by ESG (www.electrochemsci.org). This article is an open access article distributed under the terms and conditions of the Creative Commons Attribution license (http://creativecommons.org/licenses/by/4.0/). 